\title{
A general framework for evaluating executive stock options
}

\author{
Ronnie Sircar ${ }^{\mathrm{a}}$, Wei Xiong ${ }^{\mathrm{b}, *}$ \\ ${ }^{\mathrm{a}}$ ORFE Department and Bendheim Center for Finance, Princeton University, Princeton, NJ 08540, USA \\ ${ }^{\mathrm{b}}$ Department of Economics and Bendheim Center for Finance, Princeton University, Princeton, \\ NJ 08540, USA
}

Received 8 May 2005; accepted 27 July 2006

Available online 27 September 2006

\begin{abstract}
Motivated by recent recommendations by both European and American accounting standards boards that executive stock options be expensed in firms' statements, we provide an analytical and flexible framework for their evaluation. Our approach takes into account the vesting period, American style, resetting and reloading provisions that are features of many option programs, and also considers the trading restriction on executives. We identify a recursive structure in the stream of options that are granted to the executive over the course of her employment. By exploiting this, we are able to obtain a near-explicit formula for the option value. This enables us to discuss the joint effects of the different features on the exercising strategies and firms' granting cost. Especially, we highlight some significant interactions among these features.
\end{abstract}

(C) 2006 Elsevier B.V. All rights reserved.

JEL classification: G13; J33; G30; M41

Keywords: Executive stock options; American style; Vesting period; Reload; Repricing

\footnotetext{
*Corresponding author. Tel.: + 16092580282.

E-mail addresses: sircar@princeton.edu (R. Sircar), wxiong@princeton.edu (W. Xiong).
} 


\section{Introduction}

Stock options give firm executives and employees the right to buy their own firm's shares at a pre-specified strike price and so benefit from a higher share price. In the last 20 years, stock options have become an important device for firms to compensate and incentivize their executives. In the US, according to Hall and Murphy (2002), 'in fiscal 1999, 94\% of S\&P 500 companies granted options to their top executives, and the grant-date value of stock options accounted for $47 \%$ of total pay for S\&P 500 CEOs'. ${ }^{1}$

Executive stock options (ESOs) present many corporate governance challenges, including two central issues: compensation policy and financial disclosure policy. Until very recently, regulators only required firms to disclose the ESOs they had granted in footnotes too their financial statements. Whether ESOs should be expensed more directly had been widely debated in policy and academic circles through the 1990s. The proponents of expensing, as represented by Federal Reserve Chairman Alan Greenspan, financier Warren Buffett and Nobel laureate Robert Merton, strongly advocate that ESOs, as a compensation tool, should be deducted from quarterly earnings just like other compensation costs, such as salary, bonus and stocks. They argue that expensing ESOs would make firms' financial statements more transparent and make it easier for investors to monitor the compensation payout to firm executives. Some researchers, e.g., Hall and Murphy (2004), even argue that favorable accounting treatment of ESOs had fuelled their growing popularity in the 1990s. This implies that inadequate disclosure of ESOs represents a corporate governance problem - the separation of ownership and control permits executives to take actions that owners would prefer not to.

Opponents of expensing ESOs on the other hand argue that current disclosure of ESOs in footnotes is adequate enough and that explicitly expensing ESOs requires complicated evaluation models that are inaccurate and are subject to potential manipulations. The intensive lobbying of the US Senate by the high-tech industry had blocked the attempt by the Financial Accounting Standards Boards (FASB) in the 1990 s to mandate expensing. ${ }^{2}$ However, a series of corporate scandals (e.g., Enron, Worldcom and Global Crossing) have brought executive compensation and accounting transparency to the forefront of corporate governance issues for both policy makers and academic researchers. In February 2004, the International Accounting Standards Board (IASB) in Europe released its proposal for required expensing of executive stock options, followed by a similar proposal by FASB in March 2004. It appears now that proponents of expensing are winning the policy debate, but great challenges still remain on how to evaluate ESOs.

\footnotetext{
${ }^{1}$ Stock options are also a popular compensation device in Europe. As documented by Ferrarini et al. (2003), in the UK stock options represented $24 \%$ of CEO pay in 2002; for FTSE Eurotop 300 companies in 2001 , stock option programs were used in 40 of the 42 French, 25 of the 44 Italian, 17 of the 30 German, 17 of the 18 Dutch and 16 of the 19 Swedish Eurotop member companies.

${ }^{2}$ Interestingly, Arthur Levitt claims that backing down in the fight for expensing was the greatest regret during his term as the SEC commissioner.
} 
Executive stock options differ from standard market-traded options in a number of ways: ${ }^{3}$ the holders cannot sell or hedge the options, they can only exercise the option after a certain 'vesting' period, and the firm typically grants more options when the existing ones are exercised, or fall deep underwater. These complexities make it difficult to value ESOs. As Mendoza, Merton and Hancock pointed out in the Financial Times on April 2, 2004, 'valuation models for long-dated options are complex, and become more complex if they have to deal accurately with the particular characteristics of employee options'. To our knowledge, there is no convenient analytical valuation framework that takes into account the multitude of features common to ESO programs, and FASB proposes an expensing approach by simply adjusting the Black-Scholes model, which was initially derived for markettraded options. The FASB method ignores many of the particular characteristics of ESOs.

This paper provides a framework for the joint evaluation of the several special characteristics of executive stock options. By identifying a recursive structure and a scaling property in the ESOs, we obtain a near-explicit pricing formula. Our framework is useful for firms in improving the precision of expensing ESOs. It can also help to address some challenging economic questions: how do these special features interact and affect the value of ESOs, and how do they influence executives' exercising strategies? Answers to these questions can potentially help firms in structuring a more efficient compensation policy.

Typically, executive stock options are not exercisable when they are granted, but only after a vesting period of one to five years. Once vested, they can be exercised any time (American style) with a long maturity of about 10 years. In addition, firm executives are usually not allowed to sell their options. This trading restriction is essential to retain executives and to avoid a situation where they could simply receive and immediately resell their options. It means that the option recipient either has to exercise them or to forfeit them upon separation from the firm. Following Carpenter (1998), we incorporate this feature by assuming that the executive is susceptible to sudden termination of employment (voluntary or forced).

Furthermore, firms typically provide more options after large stock price increases which induce firm executives to exercise their existing options. This is known as reloading. As described by McDonald (2003), the typical reloading procedure is best explained by an example. Suppose that an executive holds 600 reload options with strike price $\$ 10$ and she exercises when the stock price is $\$ 15$. The executive surrenders $600 \times \$ 10 / \$ 15=400$ shares to pay the strike price and receives 400 new options, in addition to receiving the remaining 200 shares worth $200 \times \$ 15=\$ 3000$. $^{4}$

After large stock price drops, which cause executives' existing options to lose much of their value and incentive capacity, firms tend to reset the terms of these outof-the-money options or grant more new options. This is known as resetting or

\footnotetext{
${ }^{3}$ See, for example, Rubinstein (1995) and Section 16.2 of McDonald (2003) for an introduction to these features.

${ }^{4}$ In symbols, if $K$ denotes the strike price and $S$ the stock price when the reload option is exercised, the executive receives $K / S$ new options for each original option exercised, plus $\$(S-K)$ worth of stock.
} 
repricing. For example, as reported in McDonald (2003), after the price of Oracle stock fell from almost \$14 in August 1997 to \$7.25 in December, the firm's directors reduced the strike price of $20 \%$ of the outstanding ESOs to the market share price. Reloading and resetting of stock options are implemented in practice either through explicit contract provisions or through implicit option-granting policies. In either case, they represent economic cost to firms. Therefore, it is important to incorporate reloading and resetting in a valuation framework.

On reset or reload, the new or altered options are typically at the money. Therefore, the strike price of the option program changes over time, significantly complicating the valuation. Our analysis exploits a scaling property and a recursive structure between the option value, stock price and the strike price, leading to an analytical solution.

Our model allows us to highlight some interesting interactions among these features. For example, reloads make the option more valuable and induce its recipient to exercise quicker, while their impact depends crucially on the length of the vesting period. Anticipating the possibility of being forced to forfeit or immediately exercise the option upon the arrival of a future employment shock, the option recipient would adopt a lower exercising barrier if the probability of her early termination increases. However, the fresh vesting period for the reloaded options tends to offset such an effect. Although resetting the strike price of out-of-the-money options has often been perceived as a reward for failure, the accompanied actions of restarting the vesting period and reducing the number of options can, in many cases, reduce the value of the option program after the resetting. These examples indicate the importance of joint evaluation of different features in executive stock options.

In light of the recent debate on accounting executive stock option expenses in firms' financial statements, the difficulty in estimating executives' exercising behavior, which potentially depends on their financial constraints, risk preferences or even psychological factors, has often been raised. For example, as pointed out by Malkiel and Baumol in the Wall Street Journal on April 4, 2002, ESO valuation models 'use a profusion of variables, many of them difficult to estimate, and they yield a wide range of estimates'. Our model allows for a comparison of the effects of two variables that are directly related to option exercising: an executive's probability of exogenous early exit and her chosen exercising barrier. Our analysis indicates that the firm's cost of issuing stock options decreases greatly as the executive's probability of early termination increases, while the cost only varies modestly with respect to the exercising barrier due to the reloads. Thus, to estimate firms' option-granting cost, it is more important to form an accurate estimate of executives' employment duration than their option exercising strategies.

To demonstrate the robustness of our model, we compare it with several other methods. These methods include a fully fledged binomial tree version of our model, the approach recommended by FASB, and a simplified binomial method recently suggested by Hull and White (2004). We show that our analytical model provides reasonably close estimates of ESO values to those of the fully fledged binomial model, and our model has clear advantages over the other two. 
The rest of the paper is organized as follows. Section 2 provides a brief review of related studies on executive stock options. Section 3 specifies the executive stock option program to be analyzed. In Section 4, we provide an analytical valuation method for the executive stock option without any hedging restriction. Section 5 provides some examples for illustration. In Section 6, we demonstrate the robustness of our approach by comparing it with several other methods. Section 7 concludes the paper. All the technical proofs and details are provided in the Appendices.

\section{Related studies}

Due to the wide use of executive stock options, there is a rapidly growing literature on their valuation. One line of analysis has been on the effects of non-tradability and hedging restrictions. Huddart (1994) and Kulatilaka and Marcus (1994) develop binomial tree models to compute the certainty-equivalent (or utility-indifference) price of the (trade- and hedge-restricted) option, with non-option wealth invested in the risk-free asset. Detemple and Sundaresan (1999) solve the joint utility maximization and optimal stopping (early exercise) problem in the binomial model. Hall and Murphy (2002) use a certainty-equivalence framework to analyze the divergence between the firm's cost of issuing executive stock options and the value to executives. Rogers and Scheinkman (2003) show that portfolio constraints can lead an option recipient to exercise parts of her options over time. Henderson (2005) values European ESOs via utility indifference.

Carpenter (1998) compares a utility-indifference approach with a reduced-form model in which the option holder's suboptimal exercise due to job termination is modelled with an exogenous Poisson process (with a given stopping rate) whose first jump signals the end of the option program. This has become a common tool in modelling defaultable securities (see Duffie and Singleton, 2003). Carpenter shows that 'surprisingly, the two calibrated models perform almost identically' and that 'the stopping rate is essentially a sufficient statistic for the utility parameters'. In our model, we adopt Carpenter's approach for modelling the trading restriction. Recent papers by Hull and White (2004) and Cvitanic et al. (2004) also advocate this approach.

Several other studies have focused on individual reloading or resetting features in executive stock options. Brenner et al. (2000) provide an analytical formula for pricing a resetting provision, assuming executive stock options are European style (no early exercise). Hemmer et al. (1998) and Saly et al. (1999) adopt binomial tree methods to value reload provisions. Johnson and Tian (2000) compare a number of 'non-traditional' ESOs with a traditional European call. These include reset options and reload options (without early exercise) considered individually. Acharya et al. (2000) analyze the ex ante and ex post incentives generated by resetting the strike price of executive stock options, using a binomial model with three periods. Dybvig and Loewenstein (2003) analyze reload options and show that, under quite general conditions, and in the absence of a vesting period, they are optimally exercised as soon as the option is in the money. Kadam et al. (2003) and Henderson (2006) treat 
executive stock options as perpetual American options, but they do not deal with vesting periods and other features.

Another line of study, e.g., Carpenter (2000), Cadenillas et al. (2004) and Ross (2004), has focused on the risk-seeking incentives that can be generated by stock option grants when executives can choose the volatility or leverage level of their firms.

\section{The model}

\subsection{Executive stock option program}

Executive stock options are American call options usually granted to executives at the money. When initially given to an executive, they cannot be exercised immediately, but only after a vesting period of, typically, one to five years. Kole (1997) shows that the average minimum vesting period across firms for executive stock options is 13.5 months and the average vesting period is 23.6 months. In addition, these executive stock options usually have a long maturity of about 10 years. However, Huddart and Lang (1996) find a pervasive pattern of option exercises well before expiration by studying executives' exercising behavior in a sample of firms between 1982 and 1994.

Beyond these basic features, there are several important provisions in executive stock options. To restore incentive after executives exercise their options, more and more firms are adding a reload provision in their option programs, which explicitly entitles executives to more shares of options for each option that is exercised. As quoted by Dybvig and Loewenstein (2003), '17\% of new stock option plans in 1997 included some type of reload provision, up from 14\% in 1996'. In addition, many firms allow multiple reloads and require a new vesting period for reloaded options.

Some firms' ESOs contain a provision for maintaining incentive if the stock price falls, by directly altering the terms of existing options, specifically, by reducing the strike price and extending the maturity of existing options in this eventuality. Brenner et al. (2000) study such direct resetting of option contracts for all S\&P firms (i.e., firms in the S\&P 500, the S\&P MidCap 400 and the S\&P SmallCap 600 indices) between 1992 and 1995. They show that direct resetting on average occurred when the stock price fell to around $60 \%$ of the strike price, and the strike prices were reset to the prevailing stock prices for about $80 \%$ of these resets. The maturity was also extended for about half of the resets, and the new maturity was typically 10 years. Furthermore, Chidambaran and Prabhala (2003) find in an extended sample of firms between 1992 and 1997 that $62 \%$ of direct resettings involve restart of the vesting period, and the average exchange ratio across the resettings is $67 \%$, i.e., executives receive only two options on average for three options reset.

More pervasively, even if not explicitly stated in the original contracts, firms tend to grant more new options, either after a large stock price decrease to replace existing options which are underwater, or after a large stock price increase which induces executives to exercise their current options. Hall and Knox (2002) analyze the 
options granted to the top five executives of all S\&P firms from 1992-2000, and find a V-shaped relationship between future grant size and stock price performance. These new option grants represent implicit or indirect reloading and resetting provisions in executive stock options.

We note that current FASB rules classify implicit reloading and resetting features separately from explicit ones. Specifically, explicit reloading and resetting features are treated as fixed cost accounting which require firms to expense them directly in the granting cost, while implicit ones are considered through variable cost accounting, which allows firms to expense the additional cost once the terms of existing options are altered, or new options are issued to replace existing ones. ${ }^{5}$ Nevertheless, it is still useful to incorporate these implicit reloading and resetting features into our framework, because they represent the actual economic cost for firms. Firms need to take into account these features when they design their compensation policy. ${ }^{6}$

Based on the features of executive stock options described above, we specifically analyze an options program with the following provisions: when an option is granted, its strike price $K$ is set equal to the current stock price (at the money) as in practice. The option is American and perpetual (it has an infinite maturity). However, it can only be exercised after a vesting period of length $T$ years. Since the majority of executive stock options have long maturities in practice, and are exercised long before expiration, the assumption of an infinite maturity should not have great consequence. We will explicitly demonstrate the robustness of this assumption in Section 6. If the option is exercised in the money, say at time $\tau \geqslant T$, its holder receives the usual option payoff $S_{\tau}-K$, together with $\rho_{\mathrm{H}} K / S_{\tau}$ new options which have a new strike price $S_{\tau}$, and a new vesting period of length $T$ years. ${ }^{7}$ Furthermore, if the stock price falls to a fraction of the strike price, $l K(0<l<1)$, the option, either vested or unvested, will be replaced by $\rho_{\mathrm{L}}$ shares of new options with a new strike price $l K$ a new vesting period of a further $T$ years, and a new resetting barrier at $l^{2} K$. In summary, this option program incorporates a vesting period, reloading and resetting, as specified by parameters $T, \rho_{\mathrm{H}}, \rho_{\mathrm{L}}$ and $l .{ }^{8}$

\footnotetext{
${ }^{5}$ Explicit resettings are sometimes difficult to distinguish from implicit ones, depending on accounting guidelines. For example, the current accounting rules treat new options that are granted within six months after the cancellation of previous options as explicit resetting (See Reda et al., 2005).

${ }^{6}$ It is also worth pointing out that accounting policy could have great influence on firms' compensation policy. Before 1999, FASB did not require firms to expense the cost of resetting the strike price of underwater options and such resetting practices had been widely used by firms to revive executives' incentives after large share price drops. After FASB changed its rule by requiring firms to expense the cost of resetting in 1999, explicit resetting practices were greatly reduced.

${ }^{7}$ Although other reload structures are conceivable, in a typical reload contract, as described in Dybvig and Loewenstein (2003), for example, the holder exchanges the fraction $K / S$ of each stock she receives on exercise for the same number of new options $\left(\rho_{\mathrm{H}}=1\right)$; the remaining $1-(K / S)$ stocks contribute the $S-K$ term to the payoff.

${ }^{8}$ Our framework could also allow the strike price of new options granted at reload or reset to be a fixed fraction of the current stock price instead of being at the money. That would only introduce one more parameter, but without adding more technical difficulty.
} 


\subsection{The stock price process}

To analyze the option program, we assume that the risk-free interest rate $r$ is constant, and model the firm's stock price $\left(S_{t}\right)_{t \geqslant 0}$ by the following geometric Brownian motion:

$$
\frac{\mathrm{d} S_{t}}{S_{t}}=(\mu-q) \mathrm{d} t+\sigma \mathrm{d} Z_{t},
$$

where $q$ is the dividend yield of the firm's stock, $\sigma$ is the volatility of the stock price, $Z$ is a standard Brownian motion and $\mu$ is the total expected stock return, through both dividend and price appreciation.

Eq. (1) represents the usual price process that is used in the standard Black-Scholes option pricing model. Nevertheless, it is important to recognize several restrictions imbedded in this process. First, by treating the total stock return parameter $\mu$ as a constant independent of firm executives' incentive and effort, we potentially ignore executives' influence on stock prices. It is entirely plausible to argue that firms grant stock options because they believe that these options can motivate executives to work harder and therefore improve the firm value. One could also argue that, in an efficient stock market where investors have perfect foresight, current stock price would already incorporate the future impact that option grants might bring to the firm. Given that the goal of our model is to evaluate stock options, we will take the current stock price as given and assume that it evolves according to Eq. (1). This process has been used by most other models that are designed to evaluate ESOs. ${ }^{9}$

Second, when executives exercise their stock options, there is a potential dilution effect since the firm has to issue more shares. However, by the same token that the current stock price should already incorporate the future dilution effect, we do not explicitly deal with this issue in our model.

Third, Eq. (1) specifies a continuous dividend stream. In reality, firms usually pay discrete dividends at quarterly frequency. Discrete dividends create extra incentives for executives to exercise their options right before a dividend. Rubinstein (1995) examines such an effect and finds that the valuation of stock options is not sensitive to the assumption about dividend yield.

Finally, we assume that the option recipient's information has all been incorporated into the current stock price. While there is some evidence that executives sometimes are able to exercise their options based on non-public information (e.g., Carpenter and Remmers, 2001), regulators and firms have set various rules to prevent this from occurring. Thus, we do not incorporate option exercising by insider information in our model.

\footnotetext{
${ }^{9}$ Incorporating executives' further influence on the stock price dynamics is a great challenge that few have attempted in the literature (See Chance, 2004 for a review).
} 


\subsection{Non-tradability constraints}

The non-tradability constraint that executives are not allowed to sell their stock options makes the options less valuable to them, and less costly for the granting firm. To incorporate this effect, we suppose that the option recipient is subject to an exogenous random shock upon whose arrival she exits the firm. This shock is modelled as the first jump of a Poisson process with hazard rate $\lambda$, which implies that the recipient has an expected employment duration of $1 / \lambda$ years with the firm. When the shock hits, the option holder cannot sell the option. Instead, she has to exercise the option if it is vested, or forfeit otherwise. Even if she can exercise her current options, she would have to forfeit on reloaded new options. Since she is not allowed to sell, the exit shock affects the option value and exercising strategy.

Following Carpenter (1998) and Jennergren and Naslund (1993), we assume that the Poisson process is independent of the stock price and that the risk premium associated with these employment shocks is zero. It is plausible that executives' decision to leave the firm depends on whether their options are vested and in the money. However, estimating and incorporating the correlation between the exit rate and the stock price is difficult. Fortunately, an example provided by Rubinstein (1995) indicates that the impact of the correlation could be small (it increases the value of an option from $\$ 30.75$ to $\$ 31.63$ ).

In practice, executives often hold portfolios that are underdiversified to the firm risk. The holding of undiversified portfolios together with the non-tradability of stock options can potentially cause executives to value them at a discount relative to the granting cost of the firm, which is supposed to estimate the cost from the perspective of their shareholders who can hold well-diversified portfolios. As we discussed in Section 2, several studies have attempted to analyze the difference between executives' subjective value of the options and firms' granting cost. Most of them rely on extensive numerical analysis.

While many theoretical models suggest that executives would discount the value of stock options, the exact effect still remains an empirical issue. As reviewed by Chance (2005), the rules on how much executives can hedge their options are not clear-cut. It is strict that executives cannot short-sell stocks of their own firm, but they are not fully prohibited from trading other derivative contracts to hedge their stock options. There is also evidence that executives sell shares in response to option awards. To avoid complicating our model with these issues, we will focus our model on analyzing firms' option-granting cost by assuming that the option recipient can hedge the option (she cannot sell her option, and thus is still exposed to the exit shock). This assumption allows us to use the standard risk-neutral pricing method to derive a differential equation for the option value function. ${ }^{10}$

\footnotetext{
${ }^{10}$ Our framework can be extended to analyze executives' subjective valuation based on subjectively adjusted dividend yield rates and discount rates, following an important insight provided by Detemple and Sundaresan (1999) that the discount in executives' subjective valuation can be captured by an implicit dividend yield in the firm's stock price process.
} 


\section{Option valuation}

When the option is in the vesting period, its value is denoted by $V(S, t ; K)$, with $S$ the current stock price, $t$ the time into the vesting period and $K$ the strike price. When it is out of the vesting period, its value is denoted by $C(S ; K)$. Note that the strike price of the option might change over time due to resetting and reloading.

For a vested option, the holder optimally chooses the exercising decision. This is a standard optimal stopping problem. As widely studied by the literature (see, for example, Karatzas and Wang, 2000), the optimal strategy is to exercise the option when the stock price $S$ hits a certain level, and this level can be determined by a smooth-pasting condition. When the option is exercised, for each share, the executive will receive $\rho_{\mathrm{H}} K / S$ shares of new unvested at-the-money options (each with value $V(S, 0 ; S)$ and reset barrier $l S)$.

We then exploit a certain scaling property of the option value. Intuitively, if both the stock price and the strike price are multiplied by a positive factor, the value of the option program and the optimal exercise barrier also change by the same proportion. This property is common to many different options with call (and put) payoffs under the Black-Scholes model. ${ }^{11}$ We can then use the strike price $K$ as a scaling variable for other variables, such as the exercising level and the option value. We denote the exercising level by $h K$, with $h>1$ to be determined. Similarly, the ratio between the value of a new option $V(S, 0 ; S)$ and its strike price $S$ is a constant:

$$
D=\frac{V(S, 0 ; S)}{S}
$$

which is also to be determined. The scaling property and the fact that $D$ is a constant is verified in Proposition 4 of Appendix B.

Fig. 1 illustrates the potential payoffs from an executive stock option according to our specification using five possible paths for the stock price. The option has initial value $D K$ when it is granted. From the bottom path to the top one, respectively, the option is reset at the resetting barrier with a payoff $\rho_{\mathrm{L}} D l K$, forfeited due to an employment shock within the vesting period, exercised early due to an employment shock after the vesting period with a payoff $\max (S-K, 0)$, exercised the first time the stock price hits the exercising barrier after the vesting period or exercised immediately after the option becomes vested and the stock price is already above the exercising barrier. Both the last two scenarios end with a payoff $S-K+\rho_{\mathrm{H}} D K$.

The constant $D$ appears at both ends of these paths giving rise to the recursive nature of the problem. When deciding the optimal exercising barrier, the option recipient can take the constant $D$ in the option payoffs as given. Then, the value of $D$ can be determined by a recursive equation linking the initial value of the option with its future payoffs.

\footnotetext{
${ }^{11}$ See Gao et al. (2000) for an example.
} 


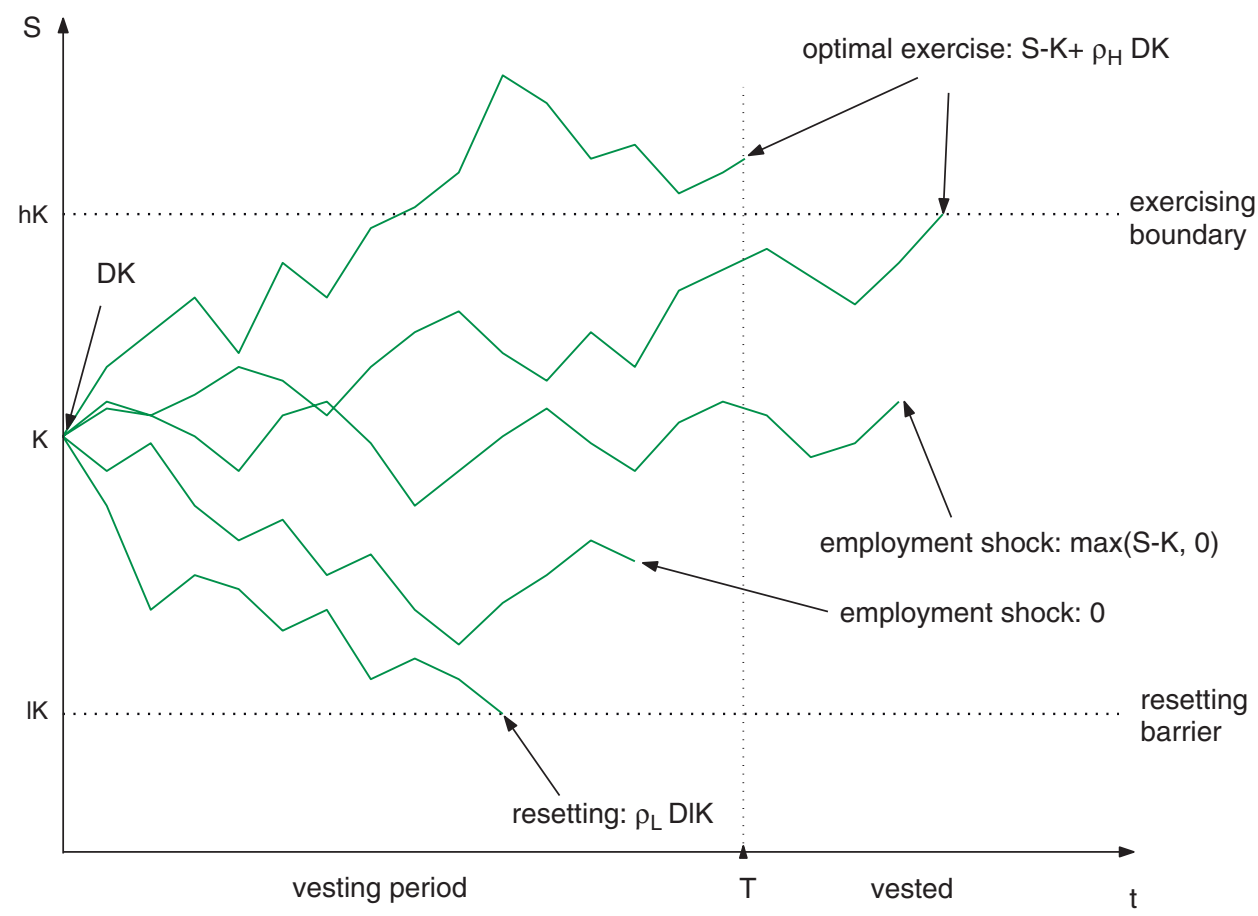

Fig. 1. The payoff structure of an executive stock option.

\subsection{Valuation of a vested option}

A vested option is similar to an American perpetual option with an additional lower resetting barrier. In the exercise region $S \geqslant h K$, its payoff, including the value of the reloaded options that are granted, is

$$
C(S ; K)=S-K+\rho_{\mathrm{H}} D K .
$$

At the resetting barrier $S=l K$, the option will be replaced by $\rho_{\mathrm{L}}$ new unvested options with value

$$
C(l K ; K)=\rho_{\mathrm{L}} D l K .
$$

In the continuation region between the lower barrier and the exercise level, $l K<S<h K, C(S ; K)$ satisfies the following ordinary differential equation:

$$
\frac{1}{2} \sigma^{2} S^{2} C_{S S}+(r-q) S C_{S}-(r+\lambda) C+\lambda \max (S-K, 0)=0 .
$$

This is simply the Black-Scholes differential equation for an infinitely lived derivative security, plus the additional term

$$
\lambda(\max (S-K, 0)-C),
$$


which captures the effect that the option may be exercised due to the employment shock with a probability $\lambda \mathrm{d} t$ over an infinitesimal time period $\mathrm{d} t .^{12}$ To determine the exercise level $h$, we employ the smooth-pasting condition

$$
C_{S}(h K ; K)=1,
$$

which enforces the condition that the option has continuous first derivative at $h K$.

Proposition 1. The solution $C(S ; K)$ of (5), satisfying (3), (4) and (6), is given by

$$
C(S ; K)= \begin{cases}S+\left(\rho_{\mathrm{H}} D-1\right) K & \text { if } S \geqslant h K, \\ a_{1} K\left(\frac{S}{K}\right)^{\kappa_{1}}+a_{2} K\left(\frac{S}{K}\right)^{\kappa_{2}}+\frac{\lambda}{\lambda+q} S-\frac{\lambda}{\lambda+r} K & \text { if } K \leqslant S<h K, \\ b_{1} K\left(\frac{S}{K}\right)^{\kappa_{1}}+b_{2} K\left(\frac{S}{K}\right)^{\kappa_{2}} & \text { if } l K \leqslant S<K,\end{cases}
$$

where

$$
\begin{aligned}
& \kappa_{1}=\frac{1}{\sigma^{2}}\left[-\left(r-q-\frac{1}{2} \sigma^{2}\right)+\sqrt{\left(r-q-\frac{1}{2} \sigma^{2}\right)^{2}+2 \sigma^{2}(\lambda+r)}\right], \\
& \kappa_{2}=\frac{1}{\sigma^{2}}\left[-\left(r-q-\frac{1}{2} \sigma^{2}\right)-\sqrt{\left(r-q-\frac{1}{2} \sigma^{2}\right)^{2}+2 \sigma^{2}(\lambda+r)}\right]
\end{aligned}
$$

and the parameters $a_{1}, a_{2}, b_{1}, b_{2}$ and $h$ solve the following algebraic equations:

$$
\begin{aligned}
& a_{1} h^{\kappa_{1}}+a_{2} h^{\kappa_{2}}-\frac{q}{\lambda+q} h=\rho_{\mathrm{H}} D-\frac{r}{\lambda+r}, \\
& a_{1} \kappa_{1} h^{\kappa_{1}-1}+a_{2} \kappa_{2} h^{\kappa_{2}-1}+\frac{\lambda}{\lambda+q}=1, \\
& a_{1}+a_{2}+\frac{\lambda(r-q)}{(\lambda+q)(\lambda+r)}=b_{1}+b_{2}, \\
& a_{1} \kappa_{1}+a_{2} \kappa_{2}+\frac{\lambda}{\lambda+q}=b_{1} \kappa_{1}+b_{2} \kappa_{2}, \\
& b_{1} l^{\kappa_{1}}+b_{2} l^{\kappa_{2}}=\rho_{\mathrm{L}} D l .
\end{aligned}
$$

Proof. See Appendix A.1.

Note that Eqs. (8)-(12) are independent of $K$, and can be used to determine the values of $a_{1}, a_{2}, b_{1}, b_{2}$ and $h$ for a given $D$.

In Appendix $\mathrm{B}$, we show that if there exists a solution of (8)-(12) with $a_{1}, a_{2}, b_{1}, b_{2} \geqslant 0$ and such that $q h>\left(r-\rho_{\mathrm{H}} D(\lambda+r)\right)$, then Eq. (7) gives the vested

\footnotetext{
${ }^{12}$ See, for example, Carr (1998) for a similar application in derivative pricing.
} 
option price, as defined by the optimal stopping problem. It is interesting to note that it is optimal for the holder to exercise early even in the case $q=0$, as long as the payoff from the reload $\left(\rho_{\mathrm{H}} D K\right)$ is large enough. While it is difficult to formulate convenient sufficient conditions on the primitive parameters $(r, q, \sigma, \lambda)$ that imply these bounds on the solution parameters $\left(a_{1}, a_{2}, b_{1}, b_{2}, h\right)$, it is a simple matter in practice to check them directly. In all the examples tested here, comprising large ranges of realistic parameter values, these conditions were satisfied.

In Appendix C, we reduce Eqs. (8)-(12) to a single nonlinear algebraic equation for $h$, and formulas for $\left(a_{1}, a_{2}, b_{1}, b_{2}\right)$ in terms of $h$. We give some simple sufficient conditions for the existence of a unique root $h \geqslant 1$.

\subsection{Valuation of an unvested option}

An unvested option is European, with its value converging to that of a vested option at the end of the vesting period:

$$
V(S, T ; K)=C(S ; K) .
$$

At the resetting barrier $S=l K$, it will be replaced by $\rho_{\mathrm{L}}$ new unvested options:

$$
V(l K, t ; K)=\rho_{\mathrm{L}} D l K, \quad 0 \leqslant t<T .
$$

Inside these boundaries $(S>l K$ and $0 \leqslant t<T)$, the unvested option price $V(S, t ; K)$ satisfies the following differential equation:

$$
V_{t}+\frac{1}{2} \sigma^{2} S^{2} V_{S S}+(r-q) S V_{S}-(r+\lambda) V=0
$$

This is similar to the standard Black-Scholes equation except for the additional term $-\lambda V$ which is again generated by the selling restriction: the option recipient may have to forfeit the option upon the arrival of a Poisson employment shock.

An unvested option is similar to a down-and-out barrier option, except that at the resetting barrier the value of the option is equal to that of the new unvested options, instead of zero. We can adapt the method of images to derive the option value in an analytical form. ${ }^{13}$ The following proposition provides $V$, given the parameters $a_{1}, a_{2}$, $b_{1}, b_{2}$ and $h$ from the valuation of the corresponding vested option.

Proposition 2. Define $g(S)$ on $S>0$ by

$$
g(S)= \begin{cases}S+\left(\rho_{\mathrm{H}} D-1\right) K-\left[b_{1} K\left(\frac{S}{K}\right)^{\kappa_{1}}+b_{2} K\left(\frac{S}{K}\right)^{\kappa_{2}}\right] & \text { if } S \geqslant h K, \\ \left(a_{1}-b_{1}\right) K\left(\frac{S}{K}\right)^{\kappa_{1}}+\left(a_{2}-b_{2}\right) K\left(\frac{S}{K}\right)^{\kappa_{2}} & \text { if } K \leqslant S<h K, \\ \quad+\frac{\lambda}{\lambda+q} S-\frac{\lambda}{\lambda+r} K & \text { if } 0<S<K,\end{cases}
$$

\footnotetext{
${ }^{13}$ See, for example, Wilmott et al. (1995) for an introduction to this method.
} 
and let $w(S, t ; K)$ be the solution of

$$
w_{t}+\frac{1}{2} \sigma^{2} S^{2} w_{S S}+(r-q) S w_{S}-(\lambda+r) w=0,
$$

in $S>0$ and $0 \leqslant t<T$, with terminal condition $w(S, T ; K)=g(S)$. Then, the value of an unvested option, for $S \geqslant l K$, is

$$
V(S, t ; K)=w(S, t ; K)-\left(\frac{S}{X}\right)^{-(k-1)} w\left(X^{2} / S, t ; K\right)+b_{1} K\left(\frac{S}{K}\right)^{\kappa_{1}}+b_{2} K\left(\frac{S}{K}\right)^{\kappa_{2}}
$$

with $k=2(r-q) / \sigma^{2}$ and $X=l K$.

Proof. See Appendix A.2.

The $V$ function in Eq. (16) contains the difference of two $w$ functions in 'images'. Both of these terms are solutions to the differential equation (13), and are designed in an exact way to cancel each other on the resetting boundary. Using the Feynman-Kac representation of the solution to (15), $w$ is given by

$$
\begin{aligned}
w(S, t ; K)= & \mathrm{e}^{-(r+\lambda)(T-t)}\left\{S \mathrm{e}^{(r-q)(T-t)} \mathrm{N}\left(d_{1}^{h}\right)-\left(1-\rho_{\mathrm{H}} D\right) K \mathrm{~N}\left(d_{2}^{h}\right)\right. \\
& +\frac{\lambda}{\lambda+q} S \mathrm{e}^{(r-q)(T-t)}\left[\mathrm{N}\left(d_{1}\right)-\mathrm{N}\left(d_{1}^{h}\right)\right]-\frac{\lambda}{\lambda+r} K\left[\mathrm{~N}\left(d_{2}\right)-\mathrm{N}\left(d_{2}^{h}\right)\right] \\
& +K\left(\frac{S}{K}\right)^{\kappa_{1}} \mathrm{e}^{\theta_{1}(T-t)}\left[\left(a_{1}-b_{1}\right) \mathrm{N}\left(d_{3}\right)-a_{1} \mathrm{~N}\left(d_{3}^{h}\right)\right] \\
& \left.+K\left(\frac{S}{K}\right)^{K_{2}} \mathrm{e}^{\theta_{2}(T-t)}\left[\left(a_{2}-b_{2}\right) \mathrm{N}\left(d_{4}\right)-a_{2} \mathrm{~N}\left(d_{4}^{h}\right)\right]\right\},
\end{aligned}
$$

where $\mathrm{N}$ is the standard normal cumulative distribution function, and we define

$$
\begin{aligned}
& \theta_{j}=\kappa_{j}\left(r-q+\frac{1}{2}\left(\kappa_{j}-1\right) \sigma^{2}\right), \quad j=1,2, \\
& d_{1}=\frac{\log (S / K)+\left(r-q+(1 / 2) \sigma^{2}\right)(T-t)}{\sigma \sqrt{T-t}}, \\
& d_{2}=\frac{\log (S / K)+\left(r-q-(1 / 2) \sigma^{2}\right)(T-t)}{\sigma \sqrt{T-t}}, \\
& d_{1}^{h}=\frac{\log (S /(h K))+\left(r-q+(1 / 2) \sigma^{2}\right)(T-t)}{\sigma \sqrt{T-t}}, \\
& d_{2}^{h}=\frac{\log (S /(h K))+\left(r-q-(1 / 2) \sigma^{2}\right)(T-t)}{\sigma \sqrt{T-t}}
\end{aligned}
$$

and

$$
\begin{array}{ll}
d_{3}=d_{2}+\kappa_{1} \sigma \sqrt{T-t}, & d_{3}^{h}=d_{2}^{h}+\kappa_{1} \sigma \sqrt{T-t}, \\
d_{4}=d_{2}+\kappa_{2} \sigma \sqrt{T-t}, & d_{4}^{h}=d_{2}^{h}+\kappa_{2} \sigma \sqrt{T-t} .
\end{array}
$$


Having found $\left(a_{1}, a_{2}, b_{1}, b_{2}, h\right)$ in terms of $D$ following Proposition 1 , the formula (16) is then used to give a nonlinear algebraic equation (2) for $D$.

\section{Discussion}

In this section, we use several examples to discuss the features of the executive stock options. For the stock price process, we use the following parameters:

$$
\sigma=42.7 \%, \quad q=1.5 \% \text {. }
$$

These are representative of individual US stocks. We assume the interest rate $r=4 \%$ and an exit rate $\lambda=0.2$, which implies an expected employment duration of five years in the firm. In addition, a typical option has the following parameter values as consistent with the standard practice described in Section 3:

$$
l=0.6, \quad \rho_{\mathrm{L}}=1.0, \quad \rho_{\mathrm{H}}=1.0, \quad T=2 .
$$

We vary each of these parameters to illustrate their effect on the option value.

\subsection{The direct effect of vesting periods}

Fig. 2 demonstrates the values of a typical option without hedging restrictions in three situations: newly issued, half into the vesting period and vested. The effect of

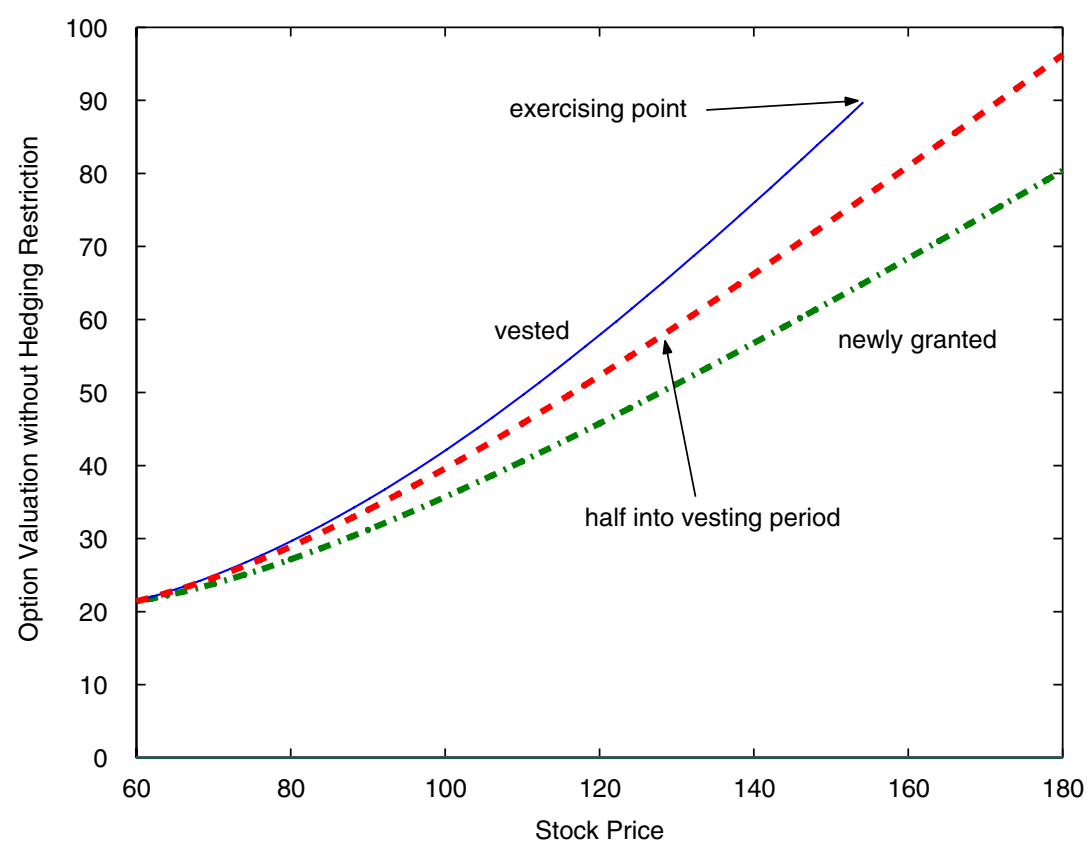

Fig. 2. Option value. The following parameters have been used: $T=2, l=0.6, \rho_{\mathrm{L}}=1, \rho_{\mathrm{H}}=1, K=100$, $r=4 \%, q=1.5 \%, \sigma=42.7 \%, \lambda=0.2$. 
the vesting period on executive stock options has received little attention in previous studies. However, our results suggest that the option value changes greatly across the vesting period. For example, the difference between the values of the option at the money $(S=100)$ when it is the newly granted and when it is vested is nearly $35 \%$ of the newly granted option value. This difference becomes even larger when the option moves into the money.

The dramatic effects of the vesting period on option values could have important economic implications for structuring the ESO program. For example, although our model treats the exit rate of the executive as exogenous, the retention power of the vesting provision, i.e., the financial value of staying with the firm during the vesting period, is substantial. This echoes the study of this issue for stocks in Kahl et al. (2003).

\subsection{Effects of reloads}

Fig. 3 (left-hand graph) illustrates the effect of reloading on the option value and the optimal exercising barrier, for three values of the vesting period: $T=1,2$ and 3 . To isolate the effect, we have set $l=0$ and $\rho_{\mathrm{L}}=0$ to remove the effect of resetting. As $\rho_{\mathrm{H}}$ goes up, the option becomes significantly more valuable. For a modest vesting period $T=2$, a reload ratio of $\rho_{\mathrm{H}}=1$ would lead to an increase of $15 \%$ in the option value. In addition, as $\rho_{\mathrm{H}}$ increases, Fig. 3 (right-hand graph) illustrates that the exercising barrier $h$ drops dramatically. Since more options will be obtained through reloading after the exercise, the recipient is willing to exercise current options for a smaller gain.

Fig. 3 (left-hand graph) also indicates that the length of the vesting period is important for the effect of reloading. When the vesting period becomes longer, the value increase caused by the reloads decreases. This is due to the fact that the reloaded new options have a fresh vesting period. Because of this, the option
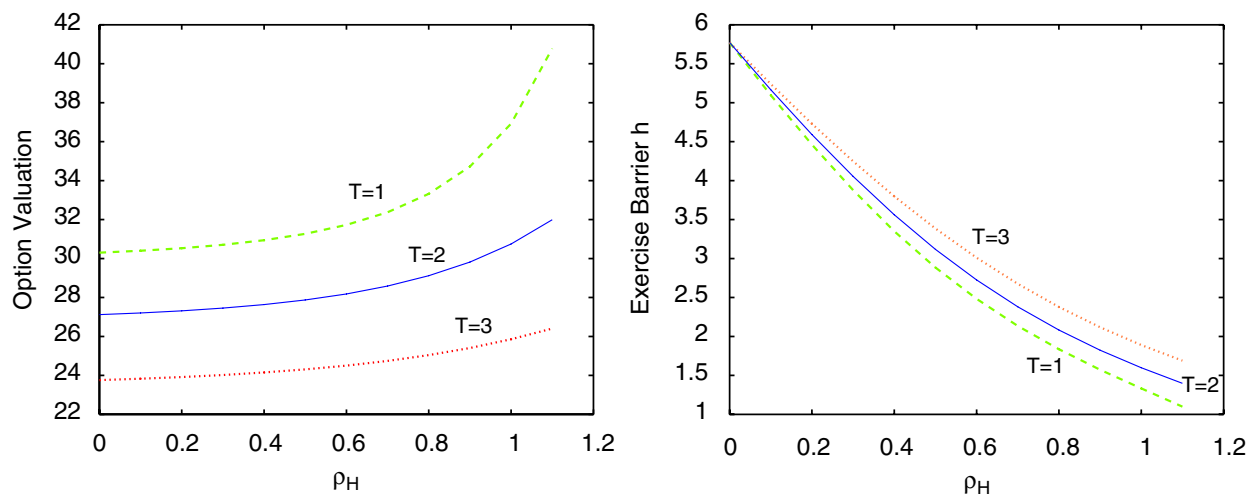

Fig. 3. The effect of reloading. The valuations are for newly granted options at the money, $V(K, 0 ; K)$. The following parameters have been used: $T=2, l=0, \rho_{\mathrm{L}}=0, K=100, r=4 \%, q=1.5 \%, \sigma=42.7 \%$, $\lambda=0.2$. 

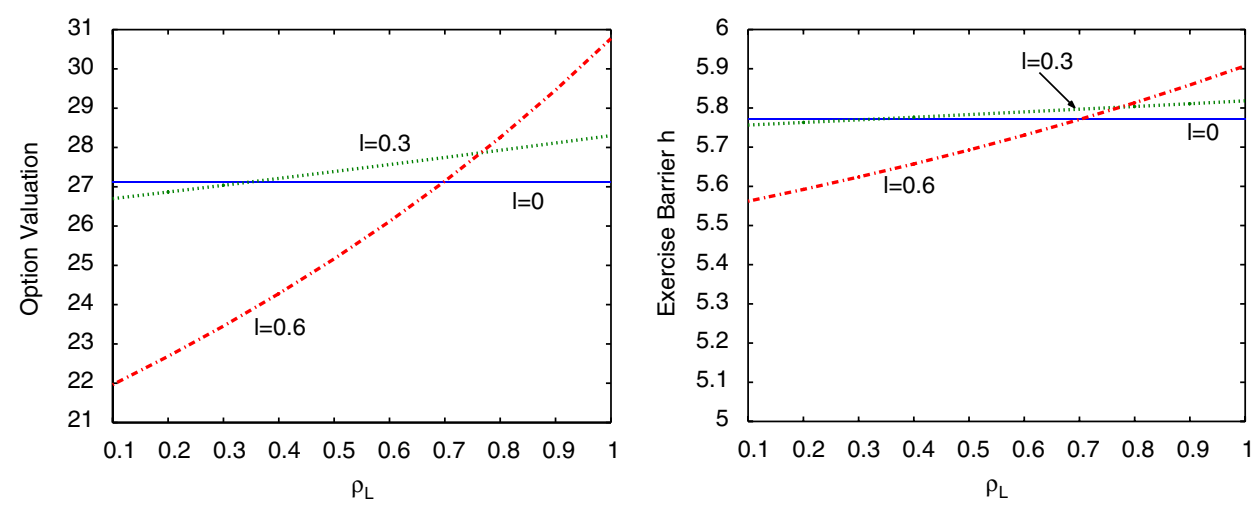

Fig. 4. The effect of resetting. The valuations are for newly granted options at the money, $V(K, 0 ; K)$. The following parameters have been used: $T=2, \rho_{\mathrm{H}}=0, K=100, r=4 \%, q=1.5 \%, \sigma=42.7 \%, \lambda=0.2$.

recipient does not simply exercise the option immediately after a vested option is in the money, which is the optimal policy suggested by Dybvig and Loewenstein (2003) in a model of reload options without vesting periods. As one would expect, as the vesting period becomes longer, the recipient would choose a higher exercising barrier, since it is more profitable to extract more gains from exercising current options rather than receiving reloaded options earlier.

Our results demonstrate that the interaction between the vesting period and the reloading provision is important for evaluating executive stock options and determining optimal exercising strategies.

\subsection{Effects of resetting}

Fig. 4 shows the effect of resetting on valuations of new option grants (left-hand graph) and on optimal exercising strategies (right-hand graph), for three different resetting barriers $l=0,0.3$ and 0.6 . We have set $\rho_{\mathrm{H}}=0$ to remove the effect of reloading. In the case $l=0$, the resetting barrier is unreachable, therefore there is no resetting effect and this case can be used as a benchmark. For the widely observed resetting barrier $l=0.6$, resetting has a significant effect on option valuation. As $\rho_{\mathrm{L}}$ goes from 0.1 to 1 , the option value varies from $\$ 22$ to $\$ 31$. The option value breaks even with the benchmark value of $\$ 27.1$ around $\rho_{\mathrm{L}}=0.7$. In this situation, the resetting provides the recipient the same value by lowering the strike price, but restarting the vesting period and reducing the number of shares at the same time. ${ }^{14}$ If $\rho_{\mathrm{L}}>0.7$, the option recipient gains value from the resetting. While if $\rho_{\mathrm{L}}<0.7$, the option recipient is effectively penalized for the stock price falling below $l K$. A similar situation arises for the resetting barrier $l=0.3$, except that the slope between option value and $\rho_{\mathrm{L}}$ is smaller and resetting only breaks even at a lower level of $\rho_{\mathrm{L}}$.

\footnotetext{
${ }^{14}$ This is sometimes called Black-Scholes repricing.
} 
According to the empirical analysis of historical repricings by Brenner et al. (2000) and Chidambaran and Prabhala (2003), firms typically reset their options when the stock price falls to $60 \%$ of the strike price, and they do so by resetting the strike price to the current stock price, restarting the vesting period and using an exchange ratio of 0.67 . In such a case, Fig. 4 suggests that the resetting would actually reduce the option value rather than increasing the option value as widely perceived by many observers. This result again indicates the importance of fully specifying all the related features in executive options even if one is interested only in the impact of a specific feature. In contrast, the exercising barrier $h$ is relatively insensitive to $\rho_{\mathrm{L}}$.

\subsection{Effects of the executive's expected employment duration}

Fig. 5 illustrates the effect of the employment shock on the option value (left-hand graph) and optimal exercising strategy (right-hand graph), for three different values of the vesting period $T=1,2$ and 3 . The exit rate $\lambda$, that is, the arrival rate of the employment shock, determines the executive's expected employment duration with the firm as $1 / \lambda$. As the exit rate goes up from 0.1 to 1 , the expected duration goes down from 10 to 1 year. As shown in the middle case of $T=2$, the option value goes from $\$ 41$ to $\$ 17$, reduced by nearly $60 \%$. The great effect of $\lambda$ on option valuation is caused by the trading restriction that the recipient is not allowed to sell the option upon her separation from the firm, but has to either exercise the option if it is vested or to forfeit otherwise. $\lambda$ also has a significant effect on the optimal exercising barrier $h$, causing it to rise from 1.45 to 2.05 . The level $h$ increases with $\lambda$ because there is a new vesting period for new options reloaded after the exercise. As $\lambda$ becomes larger, the probability that the reloaded new options vest before an employment shock
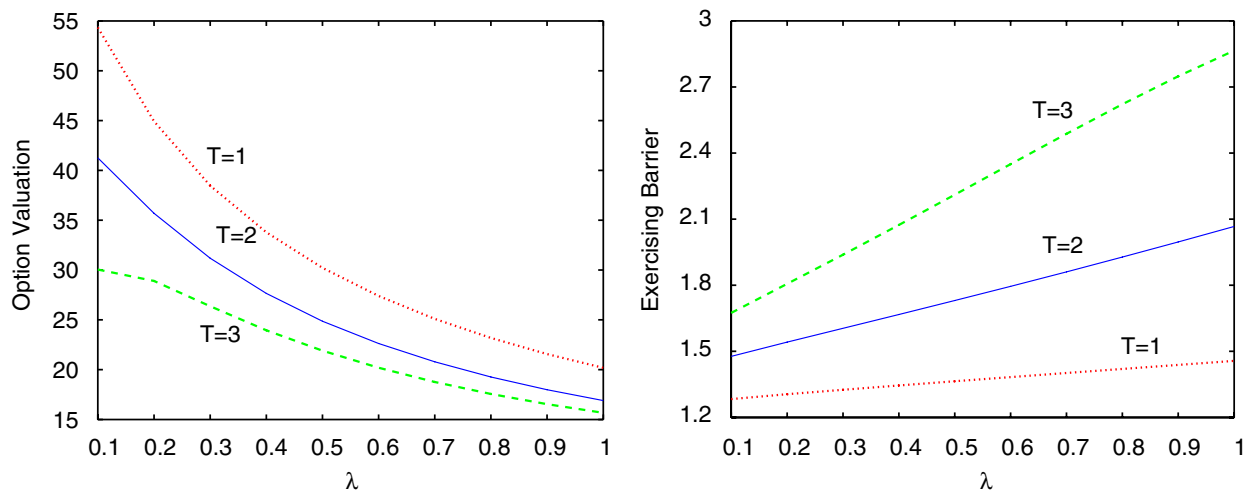

Fig. 5. The effect of exit rate. The values are for newly granted options at the money, $V(K, 0 ; K)$. The following parameters have been used: $T=2, l=0.6, \rho_{\mathrm{L}}=1.0, \rho_{\mathrm{H}}=1.0, K=100, r=4 \%, q=1.5 \%$, $\sigma=42.7 \%$. 
occurs drops. As a result, the option holder would prefer to wait longer for more profits from exercising the already vested option.

To the extent that executives often need to leave firms for exogenous reasons, our results indicate that the trading restriction has a great impact on the option value and executives' optimal exercising strategy. This effect depends critically on the length of the vesting period. As the vesting period becomes longer, the reduction in option value caused by a given exit rate becomes even bigger, and the executive waits even longer to exercise the option. This result again shows the importance of the interactions among different features of executive stock options.

\subsection{Effects of suboptimal exercising strategies}

In light of the recent debate of expensing firms' costs for issuing executive stock options from their accounting earnings, many argue that such a task might be complicated since it requires a correct calculation of option recipients' exercising strategies. While our model provides a useful tool for such a task, it could become more complex once we take into account hedging restrictions and the recipient's risk aversion which is in practice not directly observable to financial accountants. In addition, several recent studies, e.g., Heath et al. (1996), Core and Guay (2001) and Poteshman and Serbin (2003), find that many individuals exercise options in ways that are inconsistent with standard utility-maximizing preferences. To evaluate whether these individual constraints or behavioral factors will significantly affect firms' option-granting cost, we can compare the option values given various levels of $h$, which could differ from the optimal exercising barrier. These option values represent estimates of the firm's option-granting cost based on different estimates of the recipient's exercising strategy.

Fig. 6 shows the dependence of the option value on the executive's exercising strategy $h$, for three different reload coefficients and with all the other parameters, including $\lambda$, fixed. From Fig. 3, for $\rho_{\mathrm{H}}=1$ (the case of a full reload), the optimal exercise barrier is around 1.5, while for $\rho_{\mathrm{H}}=0.5$ it is around 3.2 and for $\rho_{\mathrm{H}}=0$, it is around 5.7. Surprisingly, the option value differs by less than $4 \%$ for a wide range of $h$ around the optimal barrier (from 1 to 2). This result is due to the reloading provision. If the firm has to provide more options, its granting cost of the whole option program becomes less sensitive to the executive's exercising strategy. Thus, the executive's exercising strategy is not as important as many would argue on the firm's option issuing cost. As the reload coefficient $\rho_{\mathrm{H}}$ reduces to 0.5 and 0 , the dependence of the option cost on the executive's exercising strategy becomes much higher.

In summary, our analysis shows that in the presence of full reload, executives' chosen exercising strategies have a relatively modest effect on firms' option-granting cost. While our results in Section 5.4 show that executives' early exit rate has a bigger effect. Thus, it is more important for firms to form an accurate estimate of executives' employment duration than their exercising strategies. 


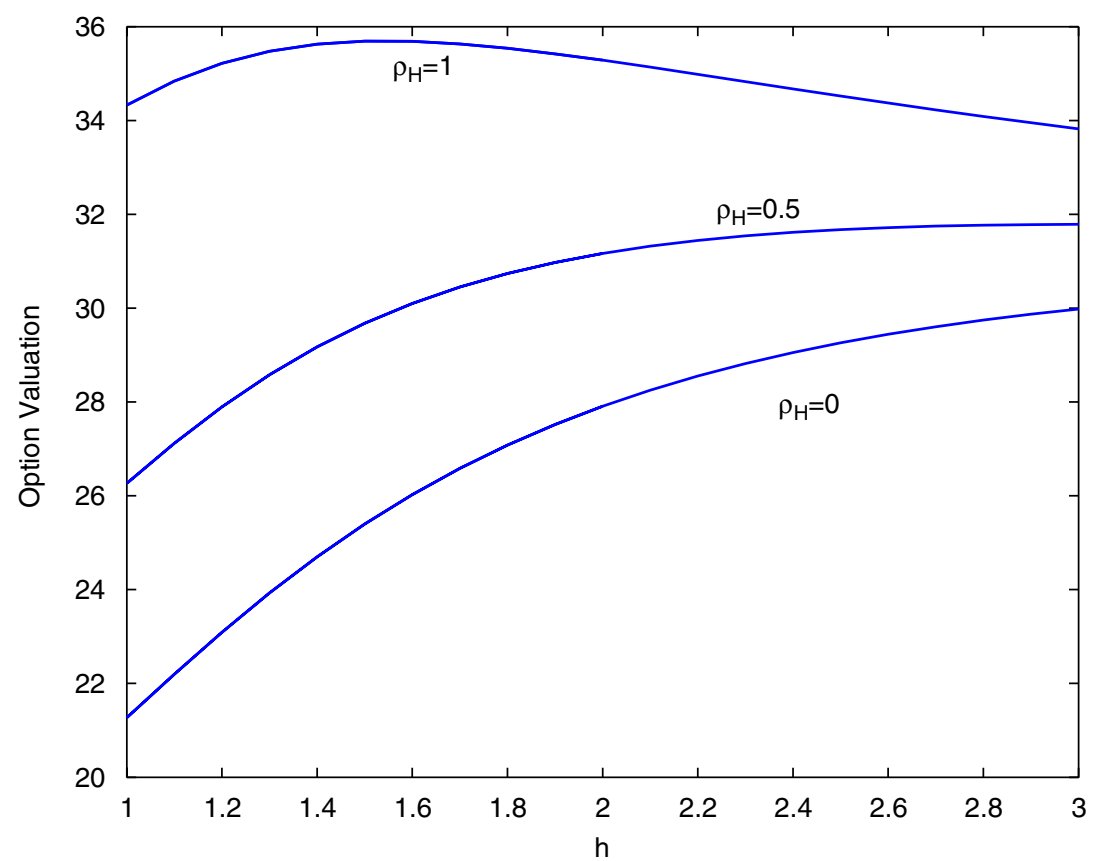

Fig. 6. The effect of suboptimal exercising strategy on option value, $V(K, 0 ; K)$. The following parameters have been used: $T=2, l=0.6, \rho_{\mathrm{L}}=1.0, \rho_{\mathrm{H}}=1.0, K=100, r=4 \%, q=1.5 \%, \sigma=42.7 \%, \lambda=0.2$.

\section{Robustness of our method}

In this section, we will discuss the robustness of our method by comparing it with several other methods: a fully fledged binomial method that incorporates finite maturity as well as the other features discussed earlier (vesting, early exit, reload and reset), the approach recommended by FASB and a simplified binomial method recently suggested by Hull and White (2004).

\subsection{Binomial version of our model}

Our approach to valuing ESOs with all the various features relies on the scaling property described in Section 4 which is a consequence of the geometric Brownian motion (Black-Scholes) model (or the i.i.d property of returns), and the fact that the call option payoff is homogeneous of degree one in the current stock price and the strike price. These also hold in a standard binomial model (which can be viewed as a consistent discretization of the Black-Scholes model), and allow us to adapt our method for this model, and thereby incorporate a finite maturity for the ESOs. Instead of an analytical formula for the initial option price in terms of the ratio $D$ (defined in (2) for the perpetual case), this relationship is computed numerically by 
working backwards through the tree. Then we solve for $D$ (for example, using the bisection algorithm). Appendix D provides details of the numerical procedures.

\subsection{FASB recommendation}

The FASB publication FAS 123, Accounting for Stock-Based Compensation, proposes a fair-value-based method of accounting for stock options. The FASB approach builds on the standard Black-Scholes option pricing model for markettraded options, and it modifies it for two major issues. First, FASB recognizes that option recipients usually exercise their options before the maturity, and it recommends treating ESOs as European options with a finite maturity equal to the expected life of the option. Second, FASB supports an adjustment for the possibility that option recipients might leave the firm during the vesting period and therefore forfeiting the option. ${ }^{15}$ However, the FASB approach does not deal with features like reloading and resetting.

\subsection{Hull-White method}

A recent paper by Hull and White (2004) proposes a modified binomial tree method to estimate the value of ESOs. Unlike the FASB approach, which treats ESOs as European options, Hull and White assume that a vested option is exercised whenever the stock price hits a certain constant barrier, or when the option reaches maturity. The exact value of the barrier is left as a free parameter. The Hull-White approach also allows for the possibility that, at each step on the tree, the option recipient might need to exit the firm for exogenous reasons, and therefore need to forfeit or exercise the option early. More recently, Cvitanic et al. (2004) provide an analytic pricing formula based on the Hull-White approach.

It is interesting to note that the constant barrier strategy assumed by Hull and White in a finite maturity framework is consistent with the optimal strategy derived from our model with its assumption of infinite maturity after vesting. Since they do not specify a barrier level, for comparison we will supply their model with the optimal barrier from our analytical model.

\subsubsection{Numerical comparison}

Table 1 reports the estimates from the aforementioned models about the example option that we discussed in the previous section. We refer to our model as the analytical VERR model (vesting, exit, reload, reset). Panel A provides the valuations for an option without any reloading or resetting. For the fully fledged binomial VERR model, we use 2000 periods, and obtain an estimate of \$26.38. Since this model does not involve any simplification, we can use this number as a benchmark to evaluate other models. It is expected that our analytical model will overestimate the

\footnotetext{
${ }^{15}$ FASB also permits firms to replace the Black-Scholes option pricing formula with binomial tree methods, which would give a similar number once a tree with enough steps is used to span the stock price during the expected lifetime of the option.
} 
Table 1

Comparing option values estimated from different models

Panel A: Vesting period, early exit (no reload or reset)

Panels A and B use the following parameters: $S=100, K=100, \sigma=42.7 \%, q=1.5 \%, r=4 \%, \lambda=0.2$, $T_{\text {vest }}=2, T_{\text {maturity }}=10, \rho_{\mathrm{H}}=0, \rho_{\mathrm{L}}=0$

\begin{tabular}{lllll} 
& VERR (binomial) & VERR (analytical) & FASB method & Hull-White \\
\hline Option value & 26.38 & 27.12 & 24.17 & $26.35^{\mathrm{a}}$
\end{tabular}

Panel B: Vesting period, early exit, reload (no reset)

\begin{tabular}{lllll} 
& VERR (binomial) & VERR (analytical) & FASB method & Hull-White \\
\hline Option value & 30.50 & 30.75 & N/A & $22.79^{\mathrm{b}}$
\end{tabular}

Panel C: Vesting period, early exit, reload and reset

This panel uses the following parameters: $S=100, K=100, \sigma=42.7 \%, q=1.5 \%, r=4 \%, \lambda=0.2$, $T_{\text {vest }}=2, T_{\text {maturity }}=10, \rho_{\mathrm{H}}=1, \rho_{\mathrm{L}}=1, l=0.6$

\begin{tabular}{lllll} 
& VERR (binomial) & VERR (analytical) & FASB method & Hull-White \\
\hline Option value & 35.71 & 35.70 & N/A & $22.51^{\mathrm{c}}$ \\
\hline
\end{tabular}

${ }^{\mathrm{a}}$ The value is based on a barrier level of $h=5.77$ from the VERR analytical model.

${ }^{\mathrm{b}}$ The value is based on a barrier level of $h=1.60$ from the VERR analytical model.

${ }^{\mathrm{c}}$ The value is based on a barrier level of $h=1.54$ from the VERR analytical model.

option value since it adopts a perpetual assumption. However, the illustrated estimation error, only $\$ 0.74$ higher than the benchmark value, is acceptable for practical purposes.

Panel A also shows that the FASB method gives a value of $\$ 24.17$, which is below the benchmark value by $\$ 2.21$. The significant difference comes from the fact that treating the ESO as a European option with the expected life of the ESO automatically assumes that the option holder will choose to exercise the option on this date even when the stock price is below a preferable level. This leads to a systematic undervaluation of the option value even with an unbiased estimate of the expected life of the option. The binomial method proposed by Hull and White (2004) generates a value of $\$ 26.35$, the last number in Panel A. Interestingly, this value is very close to the benchmark value, off only by three cents. It is important to note that this number is based on the (time-independent) optimal exercise barrier level of 5.77 derived from our analytical model.

Panel B of Table 1 provides estimates from these different models for an option with an additional reloading feature. It is interesting to note that, with the reloading feature, the price estimate from our analytical model is closer to the corresponding binomial benchmark value, off only by 25 cents. As we discussed before, the reload causes the option recipient to exercise her options earlier by choosing a lower exercise barrier $(h=1.60)$, effectively making the perpetual assumption less relevant. 
Table 2

Estimation errors by the perpetual assumption

Panel A: Varying maturity

This panel uses the following parameters: $S=100, K=100, \sigma=42.7 \%, q=1.5 \%, r=4 \%, \lambda=0.2$, $T_{\text {vest }}=2, \rho_{\mathrm{H}}=1, \rho_{\mathrm{L}}=1, l=0.6$

\begin{tabular}{llll} 
Maturity (years) & VERR (binomial) & VERR (analytical) & Estimation error (\%) \\
\hline 5 & 35.63 & 35.70 & 0.20 \\
6 & 35.68 & 35.70 & 0.06 \\
7 & 35.70 & 35.70 & 0.00 \\
8 & 35.71 & 35.70 & -0.03 \\
9 & 35.71 & 35.70 & -0.03 \\
10 & 35.71 & 35.70 & -0.03
\end{tabular}

Panel B: Varying vesting period

This panel uses the following parameters: $S=100, K=100, \sigma=42.7 \%, q=1.5 \%, r=4 \%, \lambda=0.2$, $T_{\text {maturity }}=10, \rho_{\mathrm{H}}=1, \rho_{\mathrm{L}}=1, l=0.6$

\begin{tabular}{llll} 
Vesting period (years) & VERR (binomial) & VERR (analytical) & Estimation error (\%) \\
\hline 1 & 44.91 & 44.92 & 0.03 \\
2 & 35.71 & 35.70 & -0.04 \\
3 & 28.92 & 28.91 & -0.04 \\
4 & 23.58 & 23.57 & -0.01
\end{tabular}

Panel C: Varying exit rate

This panel uses the following parameters: $S=100, K=100, \sigma=42.7 \%, q=1.5 \%, r=4 \%, T_{\text {vest }}=2$, $T_{\text {maturity }}=10, \rho_{\mathrm{H}}=1, \rho_{\mathrm{L}}=1, l=0.6$

\begin{tabular}{llll} 
Exit rate & VERR (binomial) & VERR (analytical) & Estimation error (\%) \\
\hline 0.10 & 53.57 & 53.51 & -0.12 \\
0.15 & 43.28 & 43.25 & -0.07 \\
0.20 & 35.71 & 35.70 & -0.04 \\
0.25 & 29.92 & 29.92 & 0.01
\end{tabular}

Panel D: Varying dividend yield

This panel uses the following parameters: $S=100, K=100, \sigma=42.7 \%, r=4 \%, \lambda=0.2, T_{\text {vest }}=2$, $T_{\text {maturity }}=10, \rho_{\mathrm{H}}=1, \rho_{\mathrm{L}}=1, l=0.6$

\begin{tabular}{llll} 
Dividend yield (\%) & VERR (binomial) & VERR (analytical) & Estimation error (\%) \\
\hline 0.5 & 37.68 & 37.67 & -0.02 \\
1.5 & 35.71 & 35.70 & -0.04 \\
2.5 & 33.82 & 33.81 & -0.03 \\
3.5 & 32.03 & 32.02 & -0.03
\end{tabular}

Panel E: Varying reload

This panel uses the following parameters: $S=100, K=100, \sigma=42.7 \%, q=1.5 \%, r=4 \%, \lambda=0.2$, $T_{\text {vest }}=2, T_{\text {maturity }}=10, \rho_{\mathrm{L}}=1, l=0.6$

\begin{tabular}{llll} 
Reload & VERR (binomial) & VERR (analytical) & Estimation error (\%) \\
\hline 0.0 & 30.54 & 30.77 & 0.75 \\
0.2 & 30.89 & 31.03 & 0.44
\end{tabular}


Table 2 (continued)

\begin{tabular}{|c|c|c|c|}
\hline \multicolumn{4}{|c|}{$\begin{array}{l}\text { Panel E: Varying reload } \\
\text { This panel uses the following parameters: } \\
T_{\text {vest }}=2, T_{\text {maturity }}=10, \rho_{\mathrm{L}}=1, l=0.6\end{array}$} \\
\hline Reload & VERR (binomial) & VERR (analytical) & Estimation error $(\%)$ \\
\hline 0.4 & 31.40 & 31.46 & 0.18 \\
\hline 0.6 & 32.21 & 32.22 & 0.02 \\
\hline 0.8 & 33.52 & 33.51 & -0.03 \\
\hline 1.0 & 35.71 & 35.70 & -0.04 \\
\hline \multicolumn{4}{|c|}{$\begin{array}{l}\text { Panel } F \text { : Varying reset } \\
\text { This panel uses the following parameters: } S=100, K=100, \sigma=42.7 \%, q=1.5 \%, r=4 \%, \lambda=0.2 \text {, } \\
T_{\text {vest }}=2, T_{\text {maturity }}=10, \rho_{\mathrm{H}}=1, l=0.6\end{array}$} \\
\hline Reset & VERR (binomial) & VERR (analytical) & Estimation error $(\%)$ \\
\hline 0.0 & 23.29 & 23.24 & -0.23 \\
\hline 0.2 & 25.03 & 24.98 & -0.20 \\
\hline 0.4 & 27.04 & 27.00 & -0.16 \\
\hline 0.6 & 29.42 & 29.38 & -0.14 \\
\hline 0.8 & 32.26 & 32.23 & -0.08 \\
\hline 1.0 & 35.71 & 35.70 & -0.04 \\
\hline
\end{tabular}

Panel B also shows that if we supply the optimal exercise barrier from our model to the Hull-White model, which does not deal with the reloading feature, the price estimate drops below the benchmark value by nearly eight dollars. This dramatic difference comes from two sources: one from the omission of the reloading feature which is worth $\$ 4.12$ by comparing the two benchmark values $\$ 26.38$ and $\$ 30.50$, and the other from the misuse of the exercise barrier. The exercise barrier $(h=1.60)$ is only optimal in the presence of the reload feature and the perpetual assumption. Using this barrier to evaluate the part of the option besides the reload reduces the value by $\$ 26.35-\$ 22.79=\$ 3.56$. This exercise demonstrates the importance of incorporating the reloading feature and using an appropriate exercise barrier in option valuation.

Panel C provides further value estimates when an additional resetting feature is introduced. It shows that, with the resetting feature, the price difference between our analytical model and the benchmark value reduces further to only one cent.

To further examine the magnitude of the pricing error generated by our analytical model, we report in Table 2 the differences between the option valuations estimated from the fully fledged binomial VERR model and our analytical model for a series of parameter values. In Panel A, we vary the maturity of the option from 5 to 10 years. Using the option valuations from the fully fledged binomial VERR model as the benchmarks, we can evaluate the perpetual assumption made in our analytical approach. The panel shows that with the reload, reset and vesting features, the perpetual assumption affects the ESO values by less than $0.2 \%$, well acceptable for most practical purposes. 
Panels B-F of Table 2 report the price differences by varying the values of several other model parameters, including the vesting period, the exit rate, the dividend yield, the reload and reset ratios. Across all these parameters, we find that our analytical model provides option values that are reasonably close to the values from the fully fledged binomial model: the maximum difference is $0.75 \%$, and the differences are below $0.25 \%$ for most of the cases.

\section{Conclusion}

We provide a convenient framework to analyze executive stock options under Black-Scholes assumptions, while taking into account several important features that distinguish them from standard market-traded options. Our option program not only incorporates vesting periods and trading restriction on the holders, but also specifically includes provisions of reloading and resetting. Our analysis especially highlights the importance of a joint evaluation of these features. While the reloads make the option more valuable and induce the option holder to exercise earlier, their effects depend crucially on the length of the vesting period. Anticipating the possibility of being forced to forfeit or immediately exercise the option upon the arrival of a future employment shock, the option recipient would adopt a lower exercising barrier if the exit rate increases. However, the existence of a fresh vesting period for the reloads tends to offset such an effect. Although resetting the strike price of out-of-the-money options has been often perceived as a reward for failure, the accompanying actions of restarting the vesting period and reducing the number of options can in many cases reduce the value of the option after the resetting. We also demonstrate the robustness of our model by comparing the price estimates with a full-fledged binomial model incorporating a finite maturity and the various features mentioned above, the FASB method and the Hull-White method.

\section{Acknowledgments}

We are grateful to Patrick Bolton, Markus Brunnermeier, Jennifer Carpenter, Tom Knox, Mete Soner and seminar participants at Carnegie Mellon University, Columbia University, MIT, Princeton University, University of Rochester, the Blaise Pascal Conference on Financial Modelling in Paris and the 2004 ASSA Meetings in San Diego for helpful discussions and comments.

\section{Appendix A. Some proofs}

\section{A.1. Proof of Proposition 1}

The first expression in (7) is simply the reload payoff (3) when the option is exercised above the level $h K$. Eq. (5) is a linear inhomogeneous differential equation, 
whose homogeneous part has the general solution

$$
a_{1} S^{\kappa_{1}}+a_{2} S^{\kappa_{2}}
$$

with $\kappa_{1}$ and $\kappa_{2}$ roots of the quadratic equation

$$
\frac{1}{2} \sigma^{2} \kappa(\kappa-1)+(r-q) \kappa-(\lambda+r)=0 .
$$

Since the inhomogeneous part of $(5), \lambda \max (S-K, 0)$, is piecewise linear, we can find the general solution separately for the region $K<S<h K$ and the region $l K<S<K$. This leads to the second and third expressions in (7).

Relations (8) and (9) come from enforcing continuity of the option price at $h K$ and the smooth-pasting condition (6), respectively. Conditions (10) and (11) come from enforcing continuity of the option price and its first derivative at $K$, respectively. Finally, (12) comes from the boundary condition (4) at the reset barrier.

\section{A.2. Proof of Proposition 2}

To solve the valuation function of an unvested option $V$, we define

$$
u(S, t ; K)=V(S, t ; K)-\left[b_{1} K\left(\frac{S}{K}\right)^{\kappa_{1}}+b_{2} K\left(\frac{S}{K}\right)^{\kappa_{2}}\right]
$$

It is easy to see that $u$ satisfies the differential equation in Eq. (13) with the following boundary conditions:

$$
u(l K, t ; K)=0,
$$

and

$$
u(S, T ; K)= \begin{cases}S+\left(\rho_{\mathrm{H}} D-1\right) K-\left[b_{1} K\left(\frac{S}{K}\right)^{\kappa_{1}}+b_{2} K\left(\frac{S}{K}\right)^{\kappa_{2}}\right] & \text { if } S \geqslant h K, \\ \left(a_{1}-b_{1}\right) K\left(\frac{S}{K}\right)^{\kappa_{1}}+\left(a_{2}-b_{2}\right) K\left(\frac{S}{K}\right)^{\kappa_{2}} & \text { if } K \leqslant S<h K, \\ \quad+\frac{\lambda}{\lambda+q} S-\frac{\lambda}{\lambda+r} K & \text { if } l K \leqslant S<K .\end{cases}
$$

The function $w$ satisfies Eq. (15), which is the same differential as Eq. (13). Its terminal condition is

$$
w(S, T ; K)=g(S)=u(S, T ; K) \text { for } S \geqslant l K
$$

by comparing (14) with (A.2), and

$$
w(S, T ; K)=0 \quad \text { for } 0<S<l K
$$


To show that $V$ specified in Eq. (16) satisfies the differential equation (13), we only need to show that

$$
u(S, t ; K)=w(S, t ; K)-\left(\frac{S}{X}\right)^{-(k-1)} w\left(X^{2} / S, t ; K\right) .
$$

First, let

$$
f(S, t)=\left(\frac{S}{X}\right)^{-(k-1)} w\left(X^{2} / S, t ; K\right) .
$$

Through direct, but tedious, substitutions of the partial derivatives of $f$ with that of $w$, we have

$$
\begin{aligned}
f_{t} & +\frac{1}{2} \sigma^{2} S^{2} f_{S S}+(r-q) S f_{S}-(\lambda+r) f \\
& =\left(\frac{S}{X}\right)^{-(k-1)}\left[w_{t}+\frac{1}{2} \sigma^{2} S^{2} w_{S S}+(r-q) S w_{S}-(\lambda+r) w\right]=0,
\end{aligned}
$$

the other terms cancelling, so that $f$ satisfies the same equation as $u$.

In addition, we can verify the boundary conditions:

$$
w(X, t)-\left(\frac{X}{X}\right)^{-(k-1)} w\left(X^{2} / X, t\right)=0,
$$

matching the boundary condition (A.1) for $u$, and

$$
w(S, T)-\left(\frac{S}{X}\right)^{-(k-1)} w\left(X^{2} / S, T\right)=0,
$$

which is exactly the same as the boundary condition specified in Eq. (A.2) for $S \geqslant X$ because, from (A.3), $w\left(X^{2} / S, T\right)=0$ in this region.

\section{Appendix B. Optimal stopping and variational inequality formulation}

The following proposition shows that, under appropriate conditions, Proposition 1 does indeed give the price of the vested option. The analysis utilizes the variational inequality formulation given, for example, in Karatzas and Wang (2000) or Wilmott et al. (1993).

Proposition 3. For $q \geqslant 0$ and $\lambda+r>0$, if there exists a solution of Eqs. (8)-(12) with $a_{1}, a_{2}, b_{1}, b_{2} \geqslant 0$ and such that

$$
q h>\left(r-\rho_{\mathrm{H}} D(\lambda+r)\right),
$$


then Eq. (7) gives the vested option price which is the solution of the optimal stopping problem

$$
\begin{aligned}
C(S ; K)= & \sup _{\tau} \mathbb{E}^{\star}\left\{\mathbf{1}_{\left\{\tau<\tau_{\lambda}\right\}}\left[\left(S_{\tau}-\left(1-\rho_{\mathrm{H}} D\right) K\right) \mathbf{1}_{\left\{\tau<\tau_{l}\right\}} \mathbf{1}_{\left\{S_{\tau} \geqslant K\right\}}+\rho_{\mathrm{L}} D l \mathbf{1}_{\left\{\tau_{l} \leqslant \tau\right\}}\right]\right. \\
& \left.+\mathbf{1}_{\left\{\tau>\tau_{\lambda}\right\}}\left[\rho_{\mathrm{L}} D l \mathbf{1}_{\left\{\tau_{l} \leqslant \tau_{\lambda}\right\}}+\left(S_{\tau_{\lambda}}-K\right)^{+} \mathbf{1}_{\left\{\tau_{\lambda}<\tau_{l}\right\}}\right]\right\},
\end{aligned}
$$

where $\mathbb{E}^{\star}$ denotes expectation with respect to the risk-neutral pricing measure, the supremum is over all stopping times $\tau \in[0, \infty), \tau_{l}$ denotes the first hitting time of the reset level $l K$, and $\tau_{\lambda}$ the time of the job termination shock.

The non-negativity of $\left(a_{1}, a_{2}, b_{1}, b_{2}\right)$ guarantees that $C(S ; K)$ is convex as a function of $S$, and (B.1) is necessary for the variational inequality formulation of this problem described in the following lemma.

Lemma 1. Under the conditions given in Proposition 3, C(S;K) in Eq. (7) solves the variational inequalities

$$
\begin{aligned}
& \frac{1}{2} \sigma^{2} S^{2} C_{S S}+(r-q) S C_{S}-(r+\lambda) C+\lambda \max (S-K, 0)=0, \\
& C>\left(S-\left(1-\rho_{\mathrm{H}} D\right) K\right) \mathbf{1}_{\{S \geqslant K\}},
\end{aligned}
$$

for $l K<S<h K$, and

$$
\begin{aligned}
& \frac{1}{2} \sigma^{2} S^{2} C_{S S}+(r-q) S C_{S}-(r+\lambda) C+\lambda \max (S-K, 0)<0, \\
& C=\left(S-\left(1-\rho_{\mathrm{H}} D\right) K\right) \mathbf{1}_{\{S \geqslant K\}},
\end{aligned}
$$

for $S \geqslant h K$.

Proof. As $C$ has been constructed to satisfy (B.2) and (B.5), we only need to check (B.3) and (B.4). But (B.3) is clearly true for $S<K$, and since $C$ is convex and smooth pastes to the linear function with slope 1, it also holds for $K \leqslant S<h K$. Using (B.5), denote the left-hand side of (B.4) by $L(S)$, where

$$
L(S)=-q S-\rho_{\mathrm{H}} D(\lambda+r) K+r K .
$$

Then (B.1) is equivalent to the condition $L(h K)<0$, which guarantees $L(S)<0$ for all $S \geqslant h K$.

The proof of Proposition 3 now follows from Theorem 6.7 in Karatzas and Shreve (1998), using the convexity of $C$ and the fact that $-\infty<C_{S} \leqslant 1$. The inclusion of the reset barrier represented by the hitting time $\tau_{l}$ does not affect the essential argument, and we do not repeat it here.

Finally, we verify that the scaling property holds in our option program.

\section{Proposition 4.}

1. The ratio

$$
\frac{V(S, 0 ; S)}{S}
$$

is independent of $S$. 
2. The vested option pricing function has the following form:

$$
C(S ; K)=K f(S / K)
$$

for a certain function $f$.

3. The unvested option pricing function has a similar form:

$$
V(S, t ; K)=K g(S / K, t)
$$

for a certain function $g$.

Proof. The statements follow directly by inspection of the explicit formulas in Propositions 1 and 2.

\section{Appendix C. Solutions of Eqs. (8)-(12)}

We discuss solutions of Eqs. (8)-(12) for $a_{1}, a_{2}, b_{1}, b_{2}$ and $h$, given $D$. We shall assume also that $q \geqslant 0, \lambda \geqslant 0$ and $\lambda+r>0$. Under these conditions, $\kappa_{1} \geqslant 1$ and $\kappa_{2}<0$.

Eqs. (8)-(11) constitute a linear system for $\left(a_{1}, a_{2}, b_{1}, b_{2}\right)$ which can be solved in terms of $h$ and substituted into (12) to give the nonlinear equation for $h$,

$$
p(h)=0,
$$

where

$$
\begin{aligned}
p(x)= & m_{1}\left[\kappa_{1}\left(\frac{x}{l}\right)^{-\kappa_{2}}-\kappa_{2}\left(\frac{x}{l}\right)^{-\kappa_{1}}\right]+m_{2} l\left[\left(1-\kappa_{2}\right)\left(\frac{x}{l}\right)^{1-\kappa_{1}}-\left(1-\kappa_{1}\right)\left(\frac{x}{l}\right)^{1-\kappa_{2}}\right] \\
& +c_{1} l^{\kappa_{1}}+c_{2} l^{\kappa_{2}}-\left(\kappa_{1}-\kappa_{2}\right) \rho_{\mathrm{L}} D l
\end{aligned}
$$

and

$$
\begin{aligned}
& m_{1}=\rho_{\mathrm{H}} D-\frac{r}{\lambda+r}, \\
& m_{2}=\frac{q}{\lambda+q}, \\
& c_{1}=\frac{\lambda}{\lambda+q}\left(1-\frac{\kappa_{2}(r-q)}{\lambda+r}\right), \\
& c_{2}=\frac{\lambda}{\lambda+q}\left(\frac{\kappa_{1}(r-q)}{\lambda+r}-1\right) .
\end{aligned}
$$

The following propositions give simple sufficient conditions for existence and uniqueness of a root $h \geqslant 1$ of (C.1).

Proposition 5. If

$$
D \geqslant \frac{1}{\rho_{\mathrm{H}}}\left(\frac{r-q}{\lambda+r}\right),
$$

then any root $h \in[1, \infty)$ of $(\mathrm{C} .1)$ is unique. 
Proof. Differentiating (C.2), we obtain

$$
p^{\prime}(x)=\left(\left(\frac{x}{l}\right)^{-\kappa_{2}}-\left(\frac{x}{l}\right)^{-\kappa_{1}}\right) G(x)
$$

where

$$
\begin{aligned}
G(x) & =m_{2}\left(\kappa_{1}-1\right)\left(1-\kappa_{2}\right)-m_{1} \frac{\kappa_{1} \kappa_{2}}{x} \\
& =\frac{2}{\sigma^{2}}\left(q+m_{1} \frac{(\lambda+r)}{x}\right) .
\end{aligned}
$$

For $x \geqslant 1>l$,

$$
\left(\frac{x}{l}\right)^{-\kappa_{2}}>\left(\frac{x}{l}\right)^{-\kappa_{1}}
$$

If $m_{1} \geqslant 0$, clearly $G(x) \geqslant 0$ and so $p^{\prime}(x) \geqslant 0$. If $m_{1}<0, G$ is increasing in $x$ and

$$
G(1)=\frac{2(\lambda+r)}{\sigma^{2}}\left(\rho_{\mathrm{H}} D-\frac{(r-q)}{\lambda+r}\right) .
$$

Under the bound (C.4), $G(1) \geqslant 0$ and so $G(x) \geqslant 0$ for any $x \geqslant 1$. Therefore $p^{\prime}(x) \geqslant 0$ for all $x \geqslant 1$ and any root in $[1, \infty)$ is unique.

Proposition 6. If either

$$
\rho_{\mathrm{H}}\left(\kappa_{1} l^{\kappa_{2}}-\kappa_{2} l^{\kappa_{1}}\right) \leqslant \rho_{\mathrm{L}} l\left(\kappa_{1}-\kappa_{2}\right)
$$

or

$$
D \leqslant \frac{l^{\kappa_{2}}-l^{\kappa_{1}}}{\rho_{\mathrm{H}}\left(\kappa_{1} l^{\kappa_{2}}-\kappa_{2} l^{\kappa_{1}}\right)-\rho_{\mathrm{L}} l\left(\kappa_{1}-\kappa_{2}\right)},
$$

then there exists a root $h \geqslant 1$ of (C.1).

Proof. The result follows from finding conditions such that $p(1) \leqslant 0$ and computing

$$
p(1)=l^{\kappa_{1}}-l^{\kappa_{1}}+D\left[\rho_{\mathrm{H}}\left(\kappa_{1} l^{\kappa_{2}}-\kappa_{2} l^{\kappa_{1}}\right)-\rho_{\mathrm{L}} l\left(\kappa_{1}-\kappa_{2}\right)\right] .
$$

Finally, given $h,\left(a_{1}, a_{2}, b_{1}, b_{2}\right)$ are given by

$$
\begin{aligned}
& a_{1}=\frac{1}{\kappa_{1}-\kappa_{2}}\left[-\kappa_{2} h^{-\kappa_{1}} m_{1}+h^{1-\kappa_{1}}\left(1-\kappa_{2}\right) m_{2}\right], \\
& a_{2}=\frac{1}{\kappa_{1}-\kappa_{2}}\left[\kappa_{1} h^{-\kappa_{2}} m_{1}+h^{1-\kappa_{2}}\left(\kappa_{1}-1\right) m_{2}\right], \\
& b_{1}=\frac{1}{\kappa_{1}-\kappa_{2}}\left[-m_{1} \kappa_{2} h^{-\kappa_{1}}+m_{2}\left(1-\kappa_{2}\right) h^{1-\kappa_{1}}+c_{1}\right], \\
& b_{2}=\frac{1}{\kappa_{1}-\kappa_{2}}\left[m_{1} \kappa_{1} h^{-\kappa_{2}}+m_{2}\left(\kappa_{1}-1\right) h^{1-\kappa_{2}}+c_{2}\right],
\end{aligned}
$$

where $\left(m_{1}, m_{2}, c_{1}, c_{2}\right)$ were defined in (C.3). 


\section{Appendix D. A binomial method for our model with a finite maturity}

We first describe a standard multiperiod binomial tree setup, to introduce the notation. Let $T$ denote the length of the vesting period as usual, and $T_{\exp }$ the expiration date of the ESO (including the vesting period). For an $N$-period tree, we denote the length of each period by $\Delta t=T_{\exp } / N$. Given the stock price volatility $\sigma$ and the risk-free rate $r$, we define

$$
u=\mathrm{e}^{\sigma \sqrt{\Delta t}}, \quad d=\mathrm{e}^{-\sigma \sqrt{\Delta t}}
$$

and the risk-neutral probability

$$
p=\frac{\mathrm{e}^{r \Delta t}-d}{u-d}
$$

Let $S_{n, j}$ denote the stock price at time $t_{n}=n \Delta t$ and after there have been $j$ up ticks:

$$
S_{n, j}=u^{j} d^{n-j} S_{0}, \quad j=0,1, \ldots, n, \quad n=1,2, \ldots, N .
$$

We denote by $V_{n, j}$ the ESO value at the node $(n, j)$, and we do not introduce a different notation for pre- or post-vesting. Let us suppose $n=N_{\mathrm{v}}$ denotes the end of the vesting period. The ESO price at time zero is $V_{0}$, and we define the constant

$$
D=V_{0} / S_{0},
$$

which will be determined at the last step.

Recall that $\lambda$ denotes the (risk-neutral) termination rate of the executive, so that in a time period of length $\Delta t$, she leaves the firm with probability $\lambda \Delta t$ and stays with probability $1-\lambda \Delta t$. If the option is exercised in the next period, say at time $t_{n+1}$, and if the option is vested and in the money, then the holder will receive $\rho_{\mathrm{H}}$ new fresh options worth $\rho_{\mathrm{H}} S_{0} D$ as well as the amount $S_{n+1, j}-K$. If the stock price falls to $l K$, each option is replaced by $\rho_{\mathrm{L}}$ new fresh options worth $\rho_{\mathrm{L}} l K D$.

This leads to the following algorithm for computing $V_{0}$, given an initial guess for $D$.

- Post-vesting, $j=N-1, N-2, \ldots, N_{\mathrm{v}}$, away from the lower barrier $l K$ :

$$
\begin{aligned}
V_{n, j}= & (1-\lambda \Delta t) \max \left(\mathbf{1}_{\left\{S_{n, j} \geqslant K\right\}}\left(S_{n, j}-K+\rho_{\mathrm{H}} S_{0} D\right), \mathrm{e}^{-r \Delta t}\left(p V_{n+1, j+1}+(1-p) V_{n+1, j}\right)\right) \\
& +(\lambda \Delta t) \mathrm{e}^{-r \Delta t}\left(p\left(S_{n+1, j+1}-K\right)^{+}+(1-p)\left(S_{n+1, j}-K\right)^{+}\right),
\end{aligned}
$$

with values on or below the barrier $l K$ replaced by $\rho_{\mathrm{L}} l K D$.

- Pre-vesting, $j=N_{\mathrm{v}}-1, N_{\mathrm{v}}-2, \ldots, 0$, away from the lower barrier $l K$ :

$$
V_{n, j}=(1-\lambda \Delta t) \mathrm{e}^{-r \Delta t}\left(p V_{n+1, j+1}+(1-p) V_{n+1, j}\right)+(\lambda \Delta t) \times 0,
$$

with values on or below the barrier $l K$ replaced by $\rho_{\mathrm{L}} l K D$.

Finally, we use the 'matching condition' (D.1) to determine $D$. 


\section{References}

Acharya, V., John, K., Sundaram, R., 2000. On the optimality of resetting executive stock options. Journal of Financial Economics 57, 65-101.

Brenner, M., Sundaram, R., Yermack, D., 2000. Altering the terms of executive stock options. Journal of Financial Economics 57, 103-128.

Cadenillas, A., Cvitanic, J., Zapatero, F., 2004. Leverage decision and manager compensation with choices of effort and volatility. Journal of Financial Economics 73, 71-92.

Carpenter, J., 1998. The exercise and valuation of executive stock options. Journal of Financial Economics 48, 127-158.

Carpenter, J., 2000. Does option compensation increase managerial risk appetite? Journal of Finance 55, 2311-2331.

Carpenter, J., Remmers, B., 2001. Executive stock option exercises and inside information. Journal of Business 74, 513-534.

Carr, P., 1998. Randomization and the American put. Review of Financial Studies 11, 597-626.

Chance, D., 2005. Expensing executive stock options: sorting out the issue. CFA Centre for Financial Market Integrity, forthcoming.

Chidambaran, N.K., Prabhala, N., 2003. Executive stock option repricing, internal governance mechanisms, and management turnover. Journal of Financial Economics 69, 153-189.

Core, J., Guay, W., 2001. Stock option plans for non-executive employees. Journal of Financial Economics 61, 253-287.

Cvitanic, J., Wiener, Z., Zapatero, F., 2004. Analytic pricing of employee stock options. Working Paper, University of Southern California.

Detemple, J., Sundaresan, S., 1999. Nontraded asset valuation with portfolio constraints: a binomial approach. Review of Financial Studies 12, 835-872.

Duffie, D., Singleton, K., 2003. Credit Risk. Princeton University Press, Princeton, NJ.

Dybvig, P., Loewenstein, M., 2003. Employee reload options: pricing, hedging, and optimal exercise. Review of Financial Studies 16, 145-171.

Ferrarini, G., Moloney, N., Vespro, C., 2003. Executive remuneration in the EU: comparative law and practice. ECGI Working Paper Series in Law.

Gao, B., Huang, J.-Z., Subrahmanyam, M., 2000. The valuation of American barrier options using the decomposition technique. Journal of Economic Dynamics and Control 24, 1783-1827.

Hall, B., Knox, T., 2002. Managing option fragility. NBER Working Paper 9059.

Hall, B., Murphy, K., 2002. Stock options for underdiversified executives. Journal of Accounting and Economics 33, 3-42.

Heath, C., Huddart, S., Lang, M., 1996. Psychological factors and stock option exercise. Quarterly Journal of Economics 114, 601-627.

Hemmer, T., Matsunaga, S., Shevlin, T., 1998. Optimal exercise and the cost of granting employee stock options with a reload provision. Journal of Accounting Research 36, 231-255.

Henderson, V., 2005. The impact of the market portfolio on the valuation, incentives and optimality of executive stock options. Quantitative Finance 5, 1-13.

Henderson, V., 2006. Executive exercise explained: patterns for executive stock options. Working Paper, Princeton University.

Huddart, S., 1994. Employee stock options. Journal of Accounting and Economics 18, 207-231.

Huddart, S., Lang, M., 1996. Employee stock options exercises: an empirical analysis. Journal of Accounting and Economics 21, 5-43.

Hull, J., White, A., 2004. How to value employee stock options. Financial Analysts Journal 60, 114-119.

Jennergren, L., Naslund, B., 1993. A comment on "Valuation of executive stock options and the FASB proposal". The Accounting Review 68, 179-183.

Johnson, S., Tian, Y., 2000. The value and incentive effects of nontraditional executive stock option plans. Journal of Financial Economics 57, 3-34.

Kadam, A., Lakner, P., Srinivasan, A., 2003. Executive stock options: value to the executive and cost to the firm. Working Paper, New York University. 
Kahl, M., Liu, J., Longstaff, F., 2003. Paper millionaires: how valuable is stock to a stockholder who is restricted from selling it? Journal of Financial Economics 67, 385-410.

Karatzas, I., Wang, H., 2000. A barrier option of American type. Applied Mathematics and Optimization 42, 259-279.

Karatzas, I., Shreve, S.E., 1998. Methods of mathematical finance. Springer, New York, NY.

Kole, S., 1997. The complexity of compensation contracts. Journal of Financial Economics 43, 79-104.

Kulatilaka, N., Marcus, A., 1994. Valuing employee stock options. Financial Analysts Journal November-December, 46-56.

McDonald, R., 2003. Derivatives Markets. Addison-Wesley, Reading, MA.

Poteshman, A., Serbin, V., 2003. Clearly irrational financial market behavior: evidence from the early exercise of exchange traded stock options. Journal of Finance 58, 37-70.

Reda, J., Reifler, S., Thatcher, L., 2005. Compensation Committee Handbook. Wiley, New York.

Rogers, L.C.G., Scheinkman, J., 2003. Optimal exercise of American claims when markets are not complete. Working Paper, University of Cambridge, Princeton University.

Ross, S., 2004. Compensation, incentives, and the duality of risk aversion and riskiness. Journal of Finance 59, 207-225.

Rubinstein, M., 1995. On the accounting valuation of employee stock options. Journal of Derivatives 3 , $8-24$.

Saly, P.J., Jagannathan, R., Huddart, S., 1999. Valuing the reload features of executive stock options. Accounting Horizons 13, 219-240.

Wilmott, P., Howison, S., Dewynne, J., 1995. The Mathematics of Financial Derivatives. Cambridge University Press, Cambridge. 